\title{
Structure and Kinetics of Sn Whisker Growth on Pb-free Solder Finish
}

\author{
*W. J. Choi, T. Y Lee, and K. N. Tu \\ Dept. of Materials Science and Engineering, UCLA, Los Angeles, CA 90095-1595 \\ N. Tamura, R. S. Celestre, and A. A. MacDowell \\ Advanced Light Source, LBNL, Berkeley, CA 94720 \\ Y. Y. Bong and L. Nguyen \\ National Semiconductor Corporation, Santa Clara, CA 95052 \\ George T. T. Sheng \\ Macronix international Corporation, Taiwan, ROC \\ e-mail : wjchoi@ucla.edu
}

\begin{abstract}
Standard leadframes used in surface mount technology are finished with a layer of eutectic $\mathrm{SnPb}$ for passivation and for enhancing solder wetting during reflow. When eutectic $\mathrm{SnPb}$ is replaced by $\mathrm{Pb}$-free solder, especially the eutectic $\mathrm{SnCu}$, a large number of $\mathrm{Sn}$ whiskers are found on the $\mathrm{Pb}$-free finish. Some of the whiskers are long enough to become shorts between the neighboring legs of the leadframe. How to suppress their growth and how to perform accelerated test of $\mathrm{Sn}$ whisker growth are crucial reliability issues in the electronic packaging industry. In this paper, we report the study of spontaneous $\mathrm{Sn}$ whisker growth at room temperature on eutectic $\mathrm{SnCu}$ and pure $\mathrm{Sn}$ finishes. Both compressive stress and surface oxide on Sn are necessary conditions for whisker growth. Structure and stress analyses by using the micro-diffraction in synchrotron radiation are reported. Cross-sectional electron microscopy, with samples prepared by focused ion beam, are included.
\end{abstract}

\section{Introduction of Sn whisker growth}

Whisker growth is a surface relief phenomenon. Tin (Sn) whisker is one of the most well known cases. While it is a very old subject, there is currently a renewed interest in Sn whisker growth owing to the application of $\mathrm{Pb}$-free solder in electronic manufacturing. The leadframe, which is widely used to package a chip to a board in low-end consumer electronic products, is electroplated or finished with a layer of $\mathrm{Pb}$-free solder. The $\mathrm{Pb}$-free solder finish is typically eutectic $\mathrm{SnCu}$ or pure $\mathrm{Sn}$. On the $\mathrm{SnCu}$ finish, many long $\mathrm{Sn}$ whiskers can be found and can be long enough to short two legs of the leadframe, as shown in Fig. 1(a). In Fig. 1(b), an enlarged scanning electron microscope (SEM) image of a long whisker on the $\mathrm{SnCu}$ finish is shown.

On the pure $\mathrm{Sn}$ finish surface, short whiskers were observed as shown in Fig. 1(c) and 1(d). The surface of the whisker in Fig. 1(d) is faceted. Its size is similar to the grain size in the Sn matrix. The top surface of these short whiskers is rather flat. Clearly, the morphology of the two kinds of whiskers shown in Fig. 1 is different. Besides morphology, the rate of growth is much slower on the pure $\mathrm{Sn}$ finish. The slower growth can be due to weaker driving force (stress) or

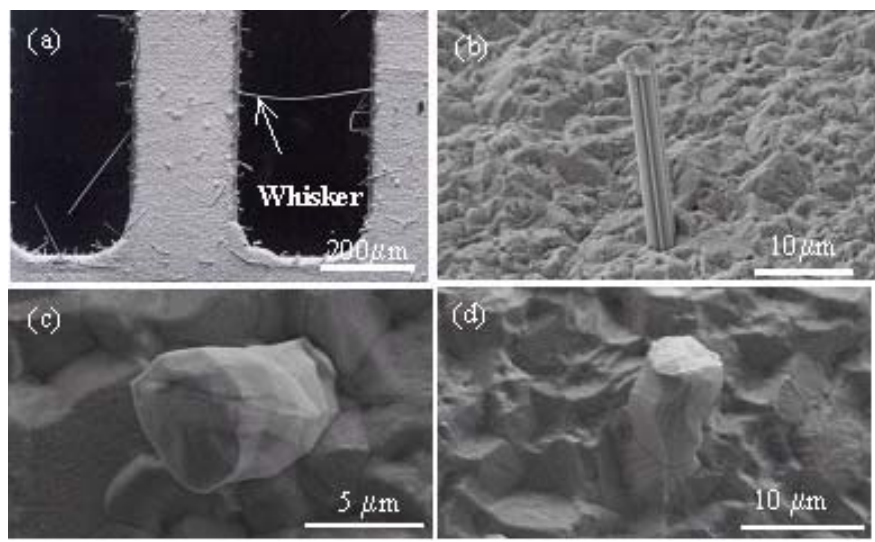

Fig. 1: SEM image of $\mathrm{Sn}$ whiskers grown on eutectic $\mathrm{SnCu}$ and Sn finish on a Leadframe. (a) A whisker shorts two of the $\mathrm{SnCu}$ leadframe legs. (b) A fluted whisker on the $\mathrm{SnCu}$ finish surface. (c),(d) Short whiskers on Sn leadframe.

slower kinetics (diffusion). Nevertheless, the $\mathrm{Cu}$ in eutectic $\mathrm{SnCu}$ seems to enhance $\mathrm{Sn}$ whisker growth.

In Fig. 2, a cross-sectional SEM image of a leadframe leg with $\mathrm{SnCu}$ finish is shown. The cross-section of the core of the $\mathrm{Cu}$ leg is rectangular, and the $\mathrm{SnCu}$ finish is a surface coating layer of 15 micron thick. A higher magnification image of the interface between the $\mathrm{SnCu}$ and $\mathrm{Cu}$ is shown in Fig. 2(b). An irregular layer of $\mathrm{Cu}_{6} \mathrm{Sn}_{5}$ intermetallic compound (IMC) can be found between the $\mathrm{Cu}$ and $\mathrm{SnCu}$. No $\mathrm{Cu}_{3} \mathrm{Sn}$ was detected, which indicates that the leadframe and the finish did not experience any temperature above $80^{\circ} \mathrm{C}$, otherwise, a thin layer of $\mathrm{Cu}_{3} \mathrm{Sn}$ should have formed in between the $\mathrm{Cu}$ and $\mathrm{Cu}_{6} \mathrm{Sn}_{5}[1]$.

\section{A brief review of Sn whisker growth}

The growth of whisker and hillock relieves the compressive stress in the matrix on which they grow. The whisker of $\mathrm{Sn}$ is known to grow from the bottom, not from the top. This is deduced from the fact that the morphology of the tip does not change during the growth. Furthermore, with a bent whisker, the part of the whisker below the bent grows longer than the part above the bent. So a whisker is being 


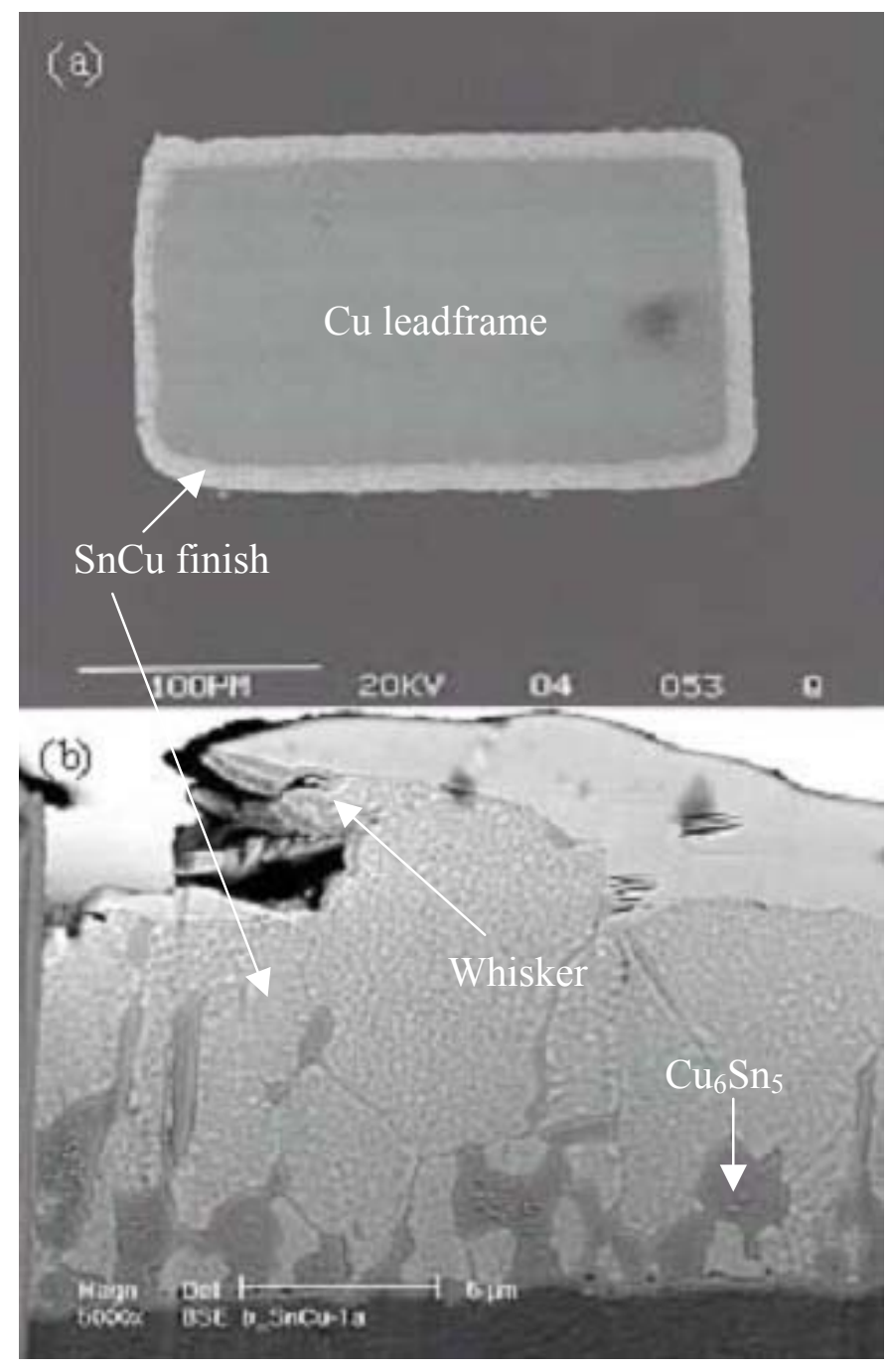

Fig. 2: (a) Cross-sectional SEM images of a leg of the $\mathrm{SnCu}$ finished leadframe. (b) An enlarged magnification of the interface between the $\mathrm{SnCu}$ finish and the $\mathrm{Cu}$ leadframe. A scallop-type $\mathrm{Cu}_{6} \mathrm{Sn}_{5}$ compound can be seen.

pushed out by compression, similar to the making of spaghetti. The origin of the compressive stress can be mechanical, thermal, or chemical. The chemical force is essential for spontaneous Sn whisker growth but less obvious. The origin of the chemical force is due to the reaction between $\mathrm{Sn}$ and $\mathrm{Cu}$ to form the intermetallic compound (IMC) of $\mathrm{Cu}_{6} \mathrm{Sn}_{5}$ at room temperature.

The diffusion of $\mathrm{Cu}$ into $\mathrm{Sn}$ and the formation of the IMC can generate compressive stress in the Sn [2]. The details of the IMC formation and stress generation will be discussed later. Since room temperature is a relatively high homologous temperature for $\mathrm{Sn}$, which melts at $237^{\circ} \mathrm{C}$, the self-diffusion of $\mathrm{Sn}$ along $\mathrm{Sn}$ grain boundaries is fast at room temperature. Therefore, the compressive stress in the $\mathrm{Sn}$ due to chemical reaction at room temperature can also be relaxed at room temperature by atomic rearrangement via grain boundary diffusion. The relaxation occurs by the removal of atomic layers of Sn normal to the stress, and these Sn atoms can diffuse along grain boundaries to the root of a whisker and push it up. Hence, the whisker growth is driven by stress and is a stress relief phenomenon. Since the reaction of $\mathrm{Sn}$ and $\mathrm{Cu}$ occurs at room temperature, the reaction continues as long as there is a supply of $\mathrm{Sn}$ and $\mathrm{Cu}$. The reaction and the growth of the compound will maintain a compressive stress to keep the whiskers growing. Hence, the Sn whisker growth is spontaneous.

Sometimes, it is puzzling to find that $\mathrm{Sn}$ whiskers seem to grow on a tensile region of the $\mathrm{Sn}$. For example, when a $\mathrm{Cu}$ leadframe surface was plated with Sn, the initial stress state of the Sn layer right after plating can be tensile, yet whisker growth was observed on the finish later. Or, if we consider the cross-section of a leadframe leg of $\mathrm{Cu}$ coated with a layer of $\mathrm{Sn}$ as shown in Fig. 2(a), the $\mathrm{Sn}$ surrounds the $\mathrm{Cu}$. The leadframe experienced a reflow heat-treatment from room temperature to $250{ }^{\circ} \mathrm{C}$ and cooled back to room temperature. Since $\mathrm{Sn}$ has a higher thermal expansion coefficient than $\mathrm{Cu}$, the $\mathrm{Sn}$ should be under tension at room temperature after the reflow, yet with time, $\mathrm{Sn}$ whisker grows, so it seems that $\mathrm{Sn}$ whisker grows under tension. Furthermore, if we bend a leadframe, one side of the leadframe will be in tension and the other side will be in compression. It is surprising to find that whiskers grow on both sides, whether the side is under mechanical compression or tension. These phenomena are hard to understand until we appreciate that the thermal stress or the mechanical stress, whether it is tension or compression, is finite and can be relaxed quickly by atomic diffusion at room temperature. After that, the continuing chemical reaction will develop the compressive stress needed to grow whiskers. These experimental phenomena show that the chemical force is persistent and essential. When we consider the driving force of spontaneous whisker growth on $\mathrm{Sn}$ or $\mathrm{Pb}$ free solder finish on $\mathrm{Cu}$, we need to include the compressive stress induced by the chemical reaction. In Fig. 2(b), the intermetallic compound can be seen in grain boundaries as well as at the interface between $\mathrm{Cu}$ and $\mathrm{SnCu}$ finish of the leadframe. This means that $\mathrm{Cu}$ from the $\mathrm{Cu}$ leadframe diffuses very fast along the grain boundary of the $\mathrm{SnCu}$ finish, reacts with $\mathrm{Sn}$, and grows intermetallic compound in the grain boundary. This intermetallic compound is $\mathrm{Cu}_{6} \mathrm{Sn}_{5}$, which exerts compressive stress.

However, the compressive stress has been found to be a necessary but insufficient condition for whisker growth. In addition to stress, we need to consider the condition of surface oxide on the Sn and the whisker surface [3]. In an ultra-high vacuum, no hillocks were found to grow on $\mathrm{Al}$ surface under compression [4]. Hillocks grow on $\mathrm{Al}$ only when the $\mathrm{Al}$ surface is oxidized. This is because without surface oxide, the free surface is itself a good source and sink of vacancies, so the compressive stress can be relieved uniformly on the entire surface of the Al on the basis of Nabarro-Herring model of creep. In the model, the relaxation can occur in each of the grains, therefore, the relaxation is uniform over the entire surface. Consequently, no localized growth of hillocks or whiskers will take place. We note that whisker or hillock is a localized growth on a surface. Whiskers, especially, are far apart from each other. To have a localized growth, the 
surface cannot be free and must be covered with oxide. The oxide must be a protective oxide so that it blocks effectively all the vacancy sources and sinks on the surface. Hence, only those metals, which grow protective oxides such as Al and Sn, are known to have hillock growth or whisker growth. For this reason, noble metals such as $\mathrm{Au}$, grow no whiskers. On the other hand, it is obvious that if the surface oxide is very thick, it will physically block the growth of any hillock and whisker. No hillocks or whiskers can penetrate a very thick oxide. Thus, the second necessary condition of whisker growth is that the protective surface oxide must not be too thick so that it can be broken at certain weak spots on the surface. From these spots whiskers grow to relieve the stress.

Since whisker growth is localized and occurs on certain spots on the Sn surface, why are these spots unique for whisker growth? Why was the surface oxide on these spots broken so easily that a whisker can nucleate and grow? Intuitively, it seems that the Sn grains or the microstructure of $\mathrm{Sn}$ at these spots should be different from their surrounding grains. In other words, there is a certain kind of structural discontinuity at these spots so that the surface oxide on these spots can be broken easily. For example, if we assume that the Sn has a texture of (100) grains, any grain on the surface with a different orientation from the surrounding textured grains is a discontinuity. This grain, under compressive stress, may become the seed of a whisker. The stress may be able to break the surface oxide along the grain boundaries between this grain and its surrounding grains. Nevertheless, this is a hypothesis without experimental verification.

Although we know that a whisker grows from the bottom, the atomic growth mechanism is unknown. There are two known mechanisms for single crystal growth. One is by absorbing atoms to the steps of a screw dislocation normal to the surface, the so-called spiral growth. Another is by absorbing atoms to kinks on surface steps, the so-called stepwise growth. Since a whisker grows from the bottom, we assume that atoms can be added to the bottom surface of a whisker by either one of these two mechanisms. Again, there is no direct observation to support either one of them yet. Since we have observed bent whiskers and twisted whiskers, the spiral growth seems unlikely.

The crystal structure of $\mathrm{Sn}$ is body-centered tetragonal $(\mathrm{a}=$ $0.58311 \mathrm{~nm}$ and $\mathrm{c}=0.31817 \mathrm{~nm}$, space group \#141). The growth direction, or the axis along the length of the whisker, has been found mostly to be either a or c, but growth along other axis has also been found. The growth rate at room temperature has been measured to be less than or close to 1 $\mathrm{mm}$ per year. This rate is fast enough to grow a whisker to short two neighboring legs of a leadframe in a few months.

The low melting point of $\mathrm{Sn}$ enables $\mathrm{Sn}$ atoms to have high self-grain boundary diffusion at room temperature. Similarly, we expect a fast room temperature grain boundary diffusion of $\mathrm{Cu}$ in $\mathrm{Sn}$ grain boundaries. Besides, it is known that noble metal atoms diffuse extremely fast in Sn by the interstitial mechanism. Thus, at room temperature $\mathrm{Cu}$ can also diffuse interstitially in the lattice of $\mathrm{Sn}$ to reach a grain boundary in the $\mathrm{Sn}$.

From the viewpoint of device reliability, how to conduct an accelerated test of Sn whisker growth and how to suppress Sn whisker growth are the most relevant issues. To achieve both of them, we need to know the parameters that affect whisker growth. Concerning the microstructure parameters, we need to know the intermetallic compound formation between the $\mathrm{Pb}$-free solder and the substrate, the surface oxide on $\mathrm{Pb}$-free solder and on the whisker, and the ambient effect on the oxide growth. The grain size and texture in the Pb-free solder, the whisker growth direction, and the relationship to neighboring grains are important. Concerning the driving force (Gibbs free energy change), we need to know the effect of pressure (compressive stress drives the growth) and temperature (optimal temperature of growth is around $60^{\circ} \mathrm{C}$ ).

\section{Synchrotron radiation micro-diffraction study of Sn whiskers}

The micro-diffraction apparatus at the Advanced Light Source in Lawrence Berkeley National Laboratory was used to study the stress to grow $\mathrm{Sn}$ whiskers on $\mathrm{SnCu}$ finishedCu leadframe at room temperature. For our experiment, we use the x-ray micro-diffraction end-station (7.3.3.) at the Advanced Light Source, which is capable of delivering white $x$-ray beam $(6-15 \mathrm{keV})$ focused to $1 \mu \mathrm{m}$ via a pair of elliptically bent Kirkpatrick-Baez mirrors. The size of the beam is smaller than the grain size of the deposited film, so that single grain white beam Laue pattern can be obtained for each individual grain. Laue patterns are collected with a large area $(9 \times 9 \mathrm{~cm})$ Charge Coupled Device (CCD) detector with an exposure time of 1 second, from which the orientation matrix and strain tensor for each illuminated grain can be derived. Because of the low absorption of x-rays, several grains through the thickness of the film are illuminated at the same time, but the grain of interest (the one closest to the surface) can be discriminated from the intensity of the reflections. The geometry of the equipment and an indexed Laue pattern from the sample are shown in Fig. 3. The sample is fixed to a computer-controlled XYZ Huber stage so that it can be scanned under the fixed micron-sized beam. An optical camera is used for coarse sample positioning. An HP Ge ORTEC detector is used to collect $\mathrm{Sn}$ and $\mathrm{Cu}$ fluorescence signal for fine positioning. The $\mathrm{SnCu}_{0.7}$ sample was prepared at National Semiconductor Corp. An area of about $100 \mu \mathrm{m} \times$ $100 \mu \mathrm{m}$ was scanned with $1.5 \mu \mathrm{m}$ step. The total number of Laue patterns is about 4300 .

Using the lattice parameters of the whisker as stressfree internal reference, the geometrical calibration parameters of the setting can be computed. The strain or stress in the grains in the $\mathrm{SnCu}$ matrix can be determined and displayed. Fig. 4(a) shows a low magnification picture of an area of finish wherein thewhisker scanned is circled. A micro-beam diffraction pattern of a whisker and its matrix is shown in Fig. 4(b). The axis along the length of the whisker was determined to be (001) of Sn, and grains in the matrix were found to show a texture of (321). 


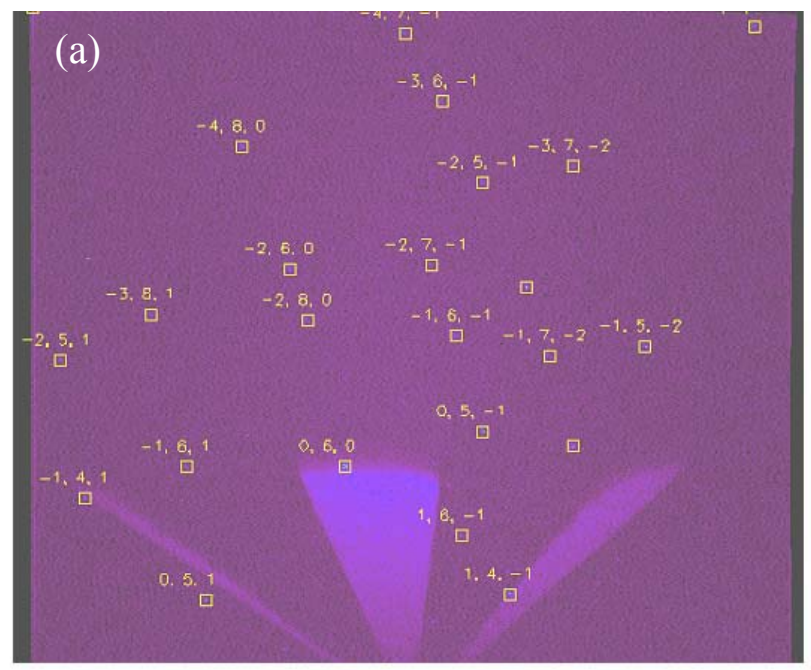

(b)

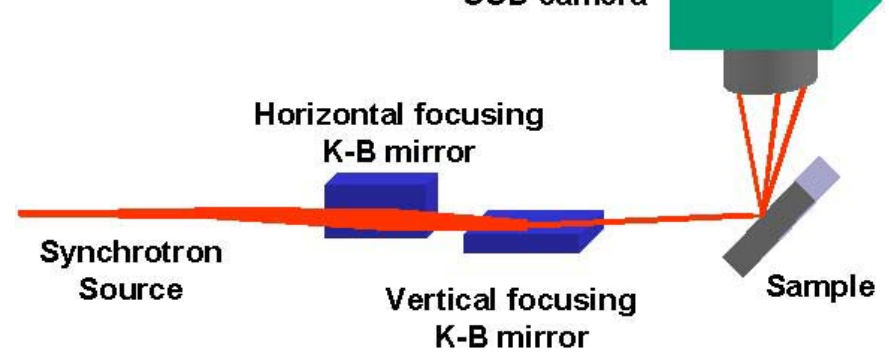

Fig. 3: (a) Micro-beam diffraction pattern (Laue pattern from whisker). (b) Schematic diagram of setting-up for microdiffraction analysis.
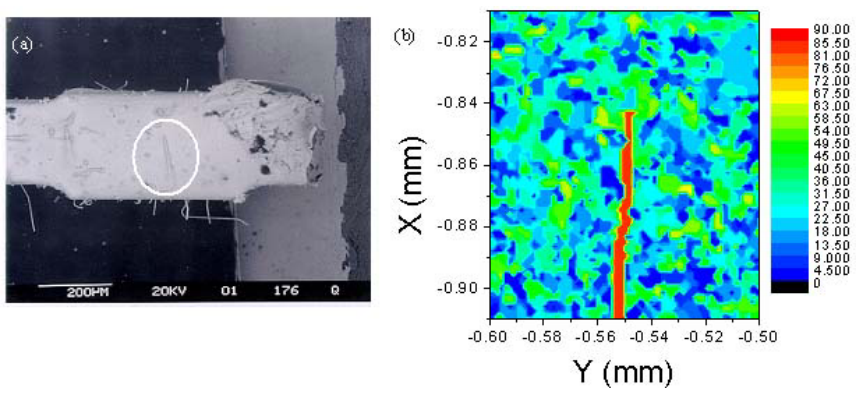

Fig. 4: (a) A low magnification picture of surface of leadframe, which is scanned by micro-diffraction. (b) Grain orientation of whisker and surface of leadframe.

The pole figures of the grains are shown in Fig. 5, in which the pole of the axis of (100), (110) and (321) and (211) are shown in Fig. 5(a) to 5(d), respectively. A high concentration of (321) at the center of the pole can be seen in Fig. 5(c). Therefore, the surface of the finish has a texture of (321) grains.

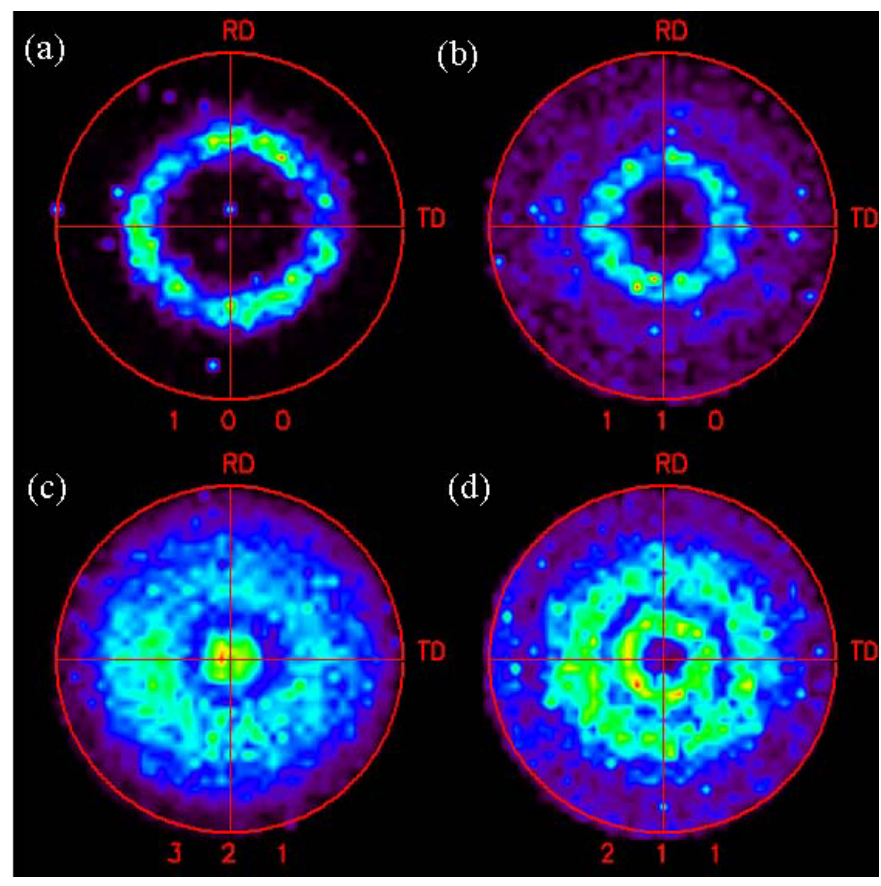

Fig. 5: Pole figures of axis (a) (100) (b) (110) (c) (321) (d) (211).

Our x-ray micro-diffraction study shows that at a local area of $100 \mu \mathrm{m} \mathrm{x} 100 \mu \mathrm{m}$, the stress is not biaxial, highly inhomogeneous with variations from grain to grain. The film is therefore biaxial only in average. Fig. 6 shows a plot of $\sigma$ 'zz, which is the deviatoric component of the stress along the surface normal. Since, $\sigma^{\prime} x x+\sigma^{\prime} y y+\sigma^{\prime} z z=0$ by definition, $-\sigma^{\prime} z z$ is a measure of the in-plane stress. A positive value of $\sigma$ 'zz indicate a overall tensile stress whereas a negative value indicates an overall compressive stress. However, the stress values (strain of less than $0.01 \%$, compared to the sensitivity of the technique of $0.005 \%$ ) are only slightly larger than the strain/stress sensitivity of the white beam Laue technique. No long range stress gradient have been observed around the root of a whisker, indicating that the growth of the whisker has released most of the local compressive stress.
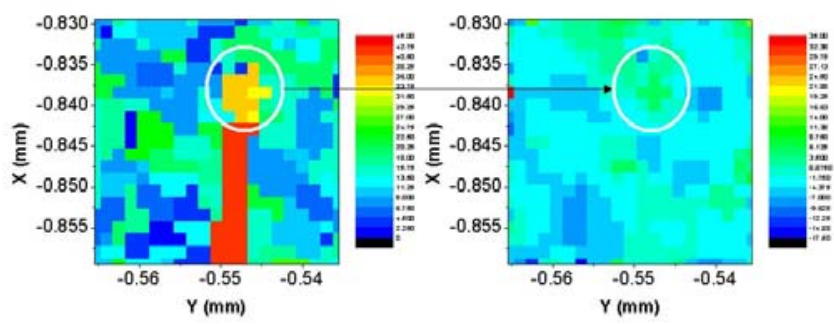

Fig. 6: Deviatoric stress along the $\mathrm{Z}$ direction around the whisker root, contribution of whisker removed

In Fig.6 the absolute value of stress in the whisker is higher than that in the surrounding grains. If we assume the whisker to be stress-free, the surface of $\mathrm{SnCu}$ finish is under compressive stress. The value of the stress is shown in table 1 . 
Table 1 In plane stress gradient around whisker root.

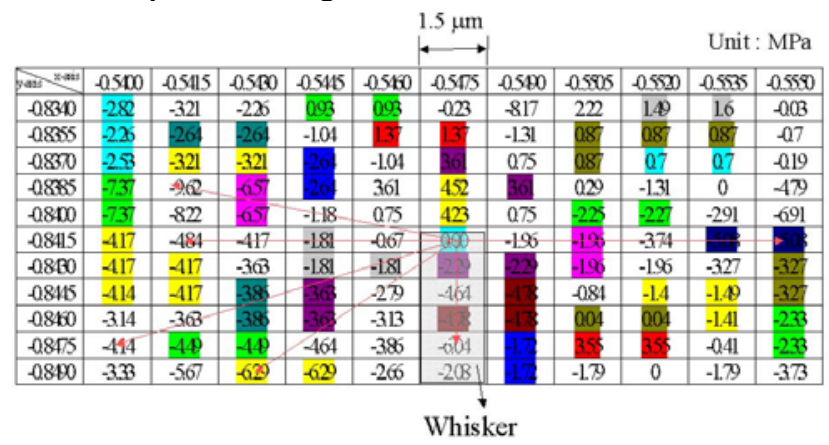

This compressive stress is quite a low value, but we can see the slight stress gradient from the whisker root area to the surroundings. This means the stress level just below the whisker is slightly less compressive than the other area. This is because the stress near the whisker is more released by the whisker growth. This is shown in table 1. Here red arrows indicate the stress gradient. Some blocks next to each other show the similar stress level, which means that they are the same grains.

\section{Accelerated whisker growth test}

Accelerated test of whisker growth is required in order to predict the lifetime of whisker growth on $\mathrm{Pb}$-free solder finish. It must be performed at temperatures above room temperature. It is possible to conduct the tests up to $60^{\circ} \mathrm{C}$, but the rate of whisker growth is still quite slow due to slow atomic diffusion. When the temperature is approaching 100 ${ }^{\circ} \mathrm{C}$, the diffusion will be faster, yet the stress will be relieved by relaxation due to the fast atomic diffusion. Hence, we encounter a situation of competition between driving force and kinetics. Although we can add $\mathrm{Cu}$ as in eutectic $\mathrm{SnCu}$ solder to have a faster whisker growth, the rate is not fast enough. Besides, we need to isolate the effect of $\mathrm{Cu}$ on whisker growth.

We propose here the use of electromigration to conduct the accelerated test of whisker growth. We recall that in the classic Blech test structure of electromigration in $\mathrm{Al}$ short strips on a baseline of $\mathrm{TiN}$, atoms of $\mathrm{Al}$ are being driven from cathode to anode and a compressive stress is built up at the anode and hillocks grow in such regions $[5,6,7]$. The advantage of using electromigration to study whisker growth is that not only we can vary the applied current density (driving force), but we can also vary the test temperature to higher temperatures (kinetics). Hence, we can control both the driving force as well as the kinetics. However, it is difficult to measure the volume of a hillock of arbitrary shape. How to change the growth of a hillock of arbitrary shape in electromigration to the growth a whisker of constant crosssection is challenging. Measuring the growth rate and the diameter of the whisker, we obtain the volume change per unit time of the whisker, $\mathrm{V}=\mathrm{JAdt} \Omega$, where $\mathrm{J}$ is the electromigration flux, $\mathrm{A}$ is the cross-section of the whisker, $\mathrm{dt}$ is unit time, and $\Omega$ is atomic volume. Then, we can calculate the stress which drives the growth on the base of Eq. (1) given in the below.

$$
\frac{d h}{d t}=\frac{2}{\ln (b / a)} \frac{\sigma_{0} \Omega s D}{k T a^{2}}
$$

To evaluate the whisker growth rate, we take $\mathrm{a}=3 \mu \mathrm{m}, \mathrm{b}$ $=0.1 \mathrm{~mm}, \sigma_{0} \Omega=0.01 \mathrm{eV}\left(\right.$ at $\left.\sigma_{0}=0.7 \times 10^{9} \mathrm{dyne} / \mathrm{cm}^{2}\right), \mathrm{kT}=$ $0.025 \mathrm{eV}$ at room temperature, $\mathrm{s}=0.3 \mathrm{~nm}$, and $\mathrm{D}=10^{-8}$ $\mathrm{cm}^{2} / \mathrm{sec}$ (the self-grain-boundary diffusivity of $\mathrm{Sn}$ at room temperature), we obtain a growth rate of $0.1 \times 10^{-8} \mathrm{~cm} / \mathrm{sec}$.

In addition, knowing $\mathrm{J}$, we have:

$$
J=C \frac{D}{k T}\left(\frac{d \sigma \Omega}{d x}+Z^{*} e j \rho\right)
$$

where $\mathrm{C}=1 / \Omega$ in pure Sn, $\mathrm{D}$ is diffusivity, $\mathrm{kT}$ is thermal energy, $\sigma$ is stress at the anode and we may assume the stress at the cathode is zero, $\mathrm{d \sigma} / \mathrm{dx}$ is the stress gradient along the short strip of Sn of length of $\mathrm{dx}, \mathrm{Z}^{*}$ is the effective charge number of the diffusing $\mathrm{Sn}$ atoms in electromigration, e is electron charge, $\mathrm{j}$ is current density, and $\rho$ is resistivity of $\mathrm{Sn}$ at the test temperature. We can determine $\sigma$ from Eq. (1), then we can check $Z^{*}$ by using Eq. (2), since we know all the other parameters.

To control the growth of the shape of a whisker at the anode, we can sputter a thin coating of quartz over the entire Sn strip with an etched hole of given diameter at the anode, as depicted in Fig. 7.

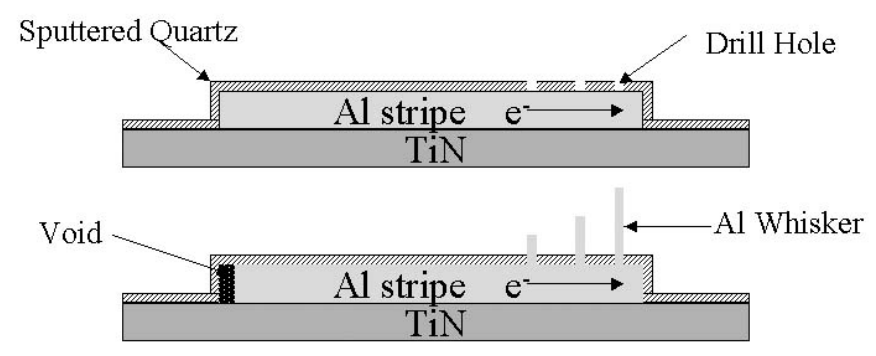

Fig. 7: Schematic diagram of sample for acceration test of $\mathrm{Sn}$ whisker growth.

With an applied current density, a whisker can be pushed out from the hole at the anode. We can measure the growth rate and the volume of the whisker as a function of current density, temperature, and time. At the same test condition, we can replace the $\mathrm{Sn}$ strip by a eutectic $\mathrm{SnCu}$ strip or a strip of a bilayer of $\mathrm{Sn} / \mathrm{Cu}$ for comparison. However, the accelerated test may not be meaningful until we can confirm that the whisker driven by electromigration has the same growth mechanism as the whisker grown spontaneously on the $\mathrm{Pb}$ free finish.

\section{Conclusions}

From the point of view of technology, the two most interesting questions about Sn whiskers are how to conduct an accelerated test of its growth and how to prevent it. We have 
considered how to use electromigration to provide the driving force and perform the accelerated tests at high temperatures. On how to prevent $\mathrm{Sn}$ whisker growth, the common approach is to remove the driving force due to $\mathrm{Cu}-\mathrm{Sn}$ reaction by adding a diffusion barrier between $\mathrm{Sn}$ and $\mathrm{Cu}$, e.g., to electroplate a thin layer of $\mathrm{Ni}$ before the electroplating of $\mathrm{Sn}$. It helps since the room temperature reaction between $\mathrm{Sn}$ and $\mathrm{Ni}$ is much slower than that between $\mathrm{Sn}$ and $\mathrm{Cu}$. Another approach is to use $\mathrm{Cu}-\mathrm{Sn}$ compounds themselves as the diffusion barrier. A heat-treatment of the leadframe at 100 to $150{ }^{\circ} \mathrm{C}$ for 10 to 30 minutes forms both $\mathrm{Cu}_{6} \mathrm{Sn}_{5}$ and $\mathrm{Cu}_{3} \mathrm{Sn}$ at the interface between $\mathrm{Sn}$ and $\mathrm{Cu}$. Since the $\mathrm{Cu}_{3} \mathrm{Sn}$ does not

form between $\mathrm{Sn}$ and $\mathrm{Cu}$ near room temperature, it is a good diffusion barrier to room temperature diffusion of $\mathrm{Cu}$ into $\mathrm{Sn}$.

\section{Acknowledgments}

The authors would like to thank the financial support of Semiconductor Research Corporation contract \#NJ-853 (Dr. Harold Hosack, contract monitor). The Advanced Light Source is supported by the Director, Office of Science, Office of Basic Energy Sciences, Materials Sciences Division, U.S. Department of Energy under Contract No. DE-AC03-

76SF00098 at Lawrence Berkeley National Laboratory.

\section{References}

1. K. N. Tu, "Interdiffusion and reaction in bimetallic $\mathrm{Cu}-\mathrm{Sn}$ thin films," Acta Metall., 21 (4) 347 (1973).

2. B.-Z. Lee and D. N. Lee, "Spontaneous growth mechanism of tin whiskers," Acta Mater., 46 (10) 3701 (1998).

3. K. N. Tu, "Irreversible processes of spontaneous whisker growth in bimetallic Cu-Sn," Phys. Rev. B, 49 (3) 2030 (1994).

4. C. Y. Chang and R. W. Vook, "The effect of surface aluminum oxide films on thermally induced hillock formation," Thin Solid Films, 228, 205 (1993).

5. I. A. Blech, "Electromigration in thin aluminum films on titanium nitride," J. Appl. Phys., 47, 1203 (1976).

6. I. A. Blech and C. Herring, "Stress generation by electromigration," Appl. Phys. Lett., 29, 131 (1976).

7. C. Y. Liu, Chih Chen, and K. N. Tu, "Electromigration of thin stripes of $\mathrm{SnPb}$ solder as a function of composition," $J$. Appl. Phys., 80, 5703 (2000). 